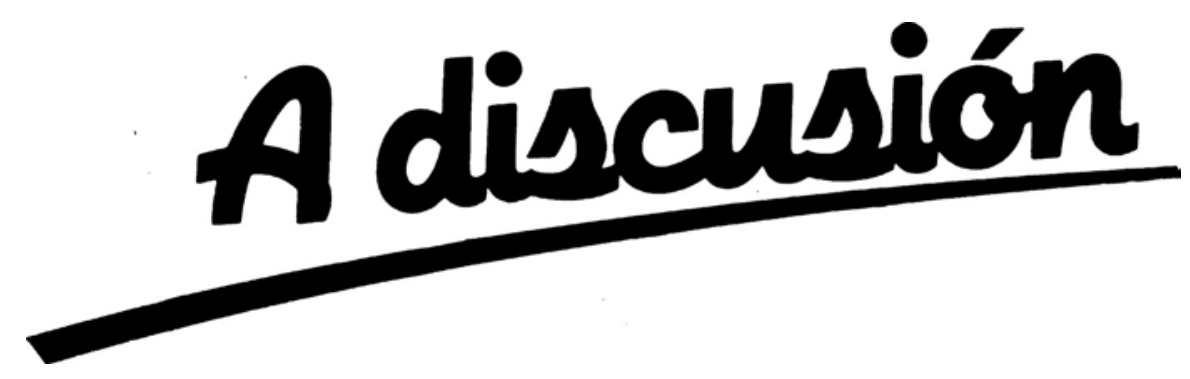

\title{
SOCIAL SECURITY REFORM AND THE SUPPORT FOR PUBLIC EDUCATION*
}

\section{Iñigo Iturbe-Ormaetxe and Guadalupe Valera ${ }^{* *}$}

WP-AD 2004-19

Corresponding author: I. Iturbe-Ormaetxe, Dpto. de Fundamentos del Análisis Económico, Universidad de Alicante, Campus San Vicente del Raspeig, 03071 Alicante, E-mail: iturbe@merlin.fae.ua.es

Editor: Instituto Valenciano de Investigaciones Económicas, S.A.

Primera Edición Mayo 2004.

Depósito Legal: V-2533-2004

IVIE working papers offer in advance the results of economic research under way in order to encourage a discussion process before sending them to scientific journals for their final publication.

*We thank Georges Casamatta, M. Dolores Collado, Ignacio Conde-Ruiz, Ana Guerrero, Carmen Herrero, Xavier Raurich, Pablo Revilla and William Thomson for helpful comments. Financial support from Spanish Ministry of Science and Technology (BEC2001-0535), Instituto Valenciano de Investigaciones Económicas, and Generalitat Valenciana (Research Project $N^{\circ}$. GV01-371) is gratefully acknowledged. The first author thanks Peter Hammond and the Department of Economics of Standford University for their hospitality and acknowledges financial support for his stay from the Secretaría de Estado de Educación y Universidades (Spanish Ministry of Education, Science and Sports) and from the University of Alicante.

** I. Iturbe-Ormaetxe: Universidad de Alicante. G. Valera: Universidad Pablo de Olavide (Sevilla) and CentrA 


\title{
SOCIAL SECURITY REFORM AND THE SUPPORT FOR PUBLIC EDUCATION
}

\author{
Iñigo Iturbe-Ormaetxe and Guadalupe Valera
}

\begin{abstract}
The provision of pensions for the old and public education for the young represent a large share of public budgets. In most Western countries, current Social Security systems are under a big financial stress. Several reforms have been proposed to solve this problem. This paper deals with the impact that some of these reforms have, through a political process, on publicly financed education. We develop a model linking both public transfer schemes, in which heterogeneous individuals vote the educational tax. Our findings show that most of the proposals that entail a partial privatization of the pension system have a negative impact on public education and, thus, on economic growth.
\end{abstract}

Fournal of Economic Literature classification numbers: D72, H55, I22, J24.

Key words: Social Security Reform, Human Capital, Public Education, Voting. 


\section{Introduction}

Several proposals have been put forward to improve the long-run solvency problems of the Social Security systems in modern economies. ${ }^{1}$ Stiglitz (2000) classifies them into two categories. In the first place, a group of proposals that only entail modest changes. They try to restore the balance of the system by either cutting down expenditures or increasing revenues. An example is the proposal of increasing the age of retirement.

In the second place, a group of more drastic reforms that involve significant structural changes. The most drastic reform would replace the unfunded defined-benefit system (also called pay-as-you-go or simply PAYGO system) currently at work in most countries, with a funded defined-contribution system, in which individuals make contributions to individual accounts. These accounts could be managed by private companies that invest contributions in assets. ${ }^{2}$ Different arguments have been suggested to convince the public about the desirability of abandoning the current PAYGO system in favor of a privatized, funded system. For example, a funded pension system is less affected by adverse demographics, it enhances savings, it gives better labor market incentives and it yields a greater rate of return. However, Geanokoplos, Mitchell and Zeldes (1998), for example, show that, once transition costs are properly taken into account, it is no longer true that a funded system could yield a greater rate of return than the current system.

Although many authors have addressed the issue of reforming pension systems, to the best of our knowledge none accounts for the implications of such proposals on other public transfer schemes or taxation levels. The objective of this paper is to study the effects of reforming public pensions systems on publicly financed education, when the tax to finance education is determined through voting.

The literature dealing with the connection existing between pension systems and public education has focused on justifying the existence of both public schemes. The standard argument is that the existence of combined public pensions and public

\footnotetext{
${ }^{1}$ See the book by Gruber and Wise (1999) for an excellent description of the problems that pension systems face in several OECD countries.

${ }^{2}$ See also Gruber and Wise (2001) for an overview of alternative reform proposals.
} 
education is in some way, the result of an implicit intergenerational contract. ${ }^{3}$ We abstract from that issue and we take both transfer schemes for granted.

Other authors have also stressed the importance of public educational policy on growth (Glomm and Ravikumar (1992), Eckstein and Zilcha (1994)). ${ }^{4}$ As most modern societies are democracies, it is obvious that there must be a widespread agreement on the fact that the government must subsidy education, out of the public budget. Also since Lucas (1988) and Becker et Al. (1990), endogenous growth models have emphasized investment in human capital as one of the main engines of growth. In this paper, we look at education as investment in human capital. So, if one of the main engines of growth is human capital, and the bulk of the investment in human capital comes from the public budget, we need to address the issue of how the proposals to reform public pension systems may affect the political will of society to support publicly financed education and, thus, on the growth rate of the economy.

We construct a model of endogenous growth where individuals live three periods. Individuals within generations are heterogeneous and selfish. ${ }^{5}$ Generations are linked through the tax-transfer system at work: In the first period of their lives, individuals attend public schools that are publicly financed. In the second period they work, and pay the education of the young and the pensions of the old. In the third period they are retired and collect their pension benefits. During the second period of their lives, agents take part in a political process where they choose the subsidy for public education. They are willing to subsidy public education today as long as this has a positive effect on their income via their future pensions. A better quality of public education today leads the economy to higher growth in the future which, in turn, will make future pensions higher. We claim that this link between future pensions and the quality of current education is a crucial aspect of an unfunded system. An unfunded system conveys that pensions of today's workers will be paid out of contributions of tomorrow's workers, who, on the other hand, are today's student. Therefore, today's

\footnotetext{
${ }^{3}$ See Becker and Murphy (1986) and, more recently, Rangel (2003) and Boldrin and Montes (2004).

${ }^{4}$ In the OECD countries, public expenditure on education represents, on average, $88 \%$ of total expenditure in educational institutions (see Education at a Glance-2002 edition).

${ }^{5}$ In this model we abstract from the issue of intergenerational altruism to stress the importance of the interrelation between both transfer schemes when evaluating reforms to the social security.
} 
workers must be interested in investing in education for the young. ${ }^{6}$ The current design of the pension system makes public education socially palatable. However, if the current system is replaced with a (partially) privatized funded system, the link between future pensions and the quality of current education becomes weaker and, in the extreme case of full privatization, completely vanishes.

The idea that there is a link between the accumulation of human capital by the young and the payment of pensions to the old was already perceived in earlier literature. ${ }^{7}$ However, this idea has not been systematically considered. Our contribution to this branch of the literature is, precisely, the development of a simple model on the political economy of public education and on endogenous growth in which the relationship between investment in human capital, through a publicly financed education, and the pension system is formally established. ${ }^{8}$ This allows us to analyze the impact of pension reform on the political support for public education.

We propose three different ways of reforming the pension systems. Two of them entail the diversion of some funds from the current PAYGO scheme to mandatory individual accounts (MIRAs). As a result, these two particular reforms always have a negative impact on the quality level of current education. We also study a reform in which the PAYGO scheme remains unchanged, and individuals are forced to make additional contributions to MIRAs. In this case, we see that the effect on education is negative only in the case when the decisive voter (the median voter) is an individual who does not save.

Finally, we consider a different scenario where some part of the agents' contribution is used to set up a fund, instead of building individual accounts. Although this type of reform could be seen as very different from the one above, we see that the effect on public education is exactly the same.

The structure of the paper is as follows. Section 2 sets up the basic model.

\footnotetext{
${ }^{6}$ In a rather different vein, Belletini and Berti-Ceroni (1999) suggest that a pure unfunded pay-asyou-go (PAYGO) system provides the taxpayers with the right incentives to support growth-oriented policies.

${ }^{7}$ See Pogue and Sgontz (1977) and Richman and Stagner (1986).

${ }^{8}$ Kaganovich and Zilcha (1999) also considered the relationship between these two public expenditures. However, in their model this link is captured by the government's social optimization who has to allocate tax revenues between these two programs.
} 
We describe the pension system in Section 3. We prove the existence of a voting equilibrium for the tax rate that finances public education in Section 4. We explore different reforms of the Social Security system and see their implications on the budget for public education in Section 5. Section 6 concludes.

\section{The Model}

Let us consider an economy populated by a continuum of families consisting of one young agent, one middle-aged and one old. Population is constant: an equal mass of each generation is alive in each period and this mass is normalized to one. Young agents go to school; middle-aged agents work, splitting their income between consumption and savings for retirement; old agents live in retirement and consume. There is no uncertainty.

We consider only two periods, labelled 0 and 1 . Those who are young at period 0 are middle-aged at period 1 , those who are middle-aged at period 0 are old at period 1, and those who are old at period 0 die at the end of that period. Agents within a generation are differentiated by the stock of human capital that they possess.

All the decisions are taken by the middle-aged agents. All of them have identical preferences over their levels of consumption in periods 0 and 1. Preferences are homothetic and they can be represented by the following additively separable utility function:

$$
v\left(c_{0}^{i}, c_{1}^{i}\right)=u\left(c_{0}^{i}\right)+\rho u\left(c_{1}^{i}\right), \text { with } \rho \in(0,1),
$$

where $c_{0}^{i}$ and $c_{1}^{i}$ are the consumption levels of individual $i$ in periods 0 and 1 , respectively, and $\rho$ represents the subjective discount rate. The function $u(\cdot)$ is increasing and concave in $c$. In order to avoid corner solutions, $u^{\prime}(0)=+\infty$.

Production takes place according to a constant-returns-to scale technology represented by a production function similar to that of De Gregorio (1996) and Galor and Tsiddon (1997):

$$
Y_{t}=F\left(K_{t}, h_{t} L_{t}\right) \equiv h_{t} L_{t} f\left(k_{t}\right)
$$

where $k_{t} \equiv \frac{K_{t}}{h_{t} L_{t}}, Y_{t}$ is aggregate output, $K_{t}$ is aggregate capital, $h_{t}$ is the average level 
of human capital, and $L_{t}$ is aggregate (raw) labor. The second input, $h_{t} L_{t}$, can be seen as efficiency labor. The function $f\left(k_{t}\right)$ has all the standard properties needed to guarantee the existence of an interior solution to the producers' profit maximization problem. Producers operate in a perfectly competitive market. Then:

$$
\begin{aligned}
1+r_{t} & =f^{\prime}\left(k_{t}\right) \\
w_{t} & =f\left(k_{t}\right)-f^{\prime}\left(k_{t}\right) k_{t},
\end{aligned}
$$

where $r_{t}$ is the rate of interest and $w_{t}$ is the real wage per efficiency unit of labor.

We take $r_{t}$ as given at the world level $r$. This assumption is often called "small open economy" in the literature (see Galor and Tsiddon(1997)). This implies that $k_{t}$ and $w_{t}$ are also fixed. We set $w_{t} \equiv 1$. Note that, as population is constant, the only source of growth is $h_{t}$, the average level of human capital.

In period 0, every middle-aged agent has one unit of labor time which she supplies inelastically. She earns a pre-tax salary $h_{0}^{i}$, interpreted as her stock of human capital. Human capital is distributed on some interval $[a, b] \subset(0,+\infty)$, according to some distribution function $G\left(h_{0}^{i}\right)$, with mean $h_{0}$ and median $h_{0}^{m}$.

Next we describe the technology of human capital accumulation. Following Glomm and Ravikumar (1992), the stock of human capital of each offspring in period 1 is determined by the stock of human capital of the parent and by the "quality" of public education, denoted by $e$. Specifically,

$$
h_{1}^{i}=\theta\left(e, h_{0}^{i}\right),
$$

with $\theta_{e}>0, \theta_{e e}<0, \theta_{h}>0, \theta_{h h}<0$ and $\theta\left(0, h_{0}^{i}\right)=\theta(e, 0)=0$. These assumptions are standard. Both factors ( $e$ and $h_{0}^{i}$ ) have a positive effect, but diminishing returns apply. Note also that we are assuming implicitly that the young have no resources to invest in their own education.

The role of the government is twofold. First, the government manages the Social Security system. This Social Security system imposes a payroll tax on wages. Individuals are entitled to a pension benefit when they are old. Workers contribute a 
fraction $\lambda_{0}$ of their salary in period 0 . When retired in period 1 , they get a pension benefit $b_{1}^{i}$. In the next section, we describe the pension system in detail.

Second, the government collects a proportional tax $\tau$ on labor income to finance public schools. Then, total revenue for the schools is:

$$
\int_{0}^{\infty} \tau h_{0}^{i} d G\left(h_{0}^{i}\right)=\tau h_{0} .
$$

The quality of public education $e$ is a function of total revenue. We write $e=\varphi\left(\tau h_{0}\right)$, where $\varphi^{\prime}>0, \varphi^{\prime \prime} \leq 0$ and $\varphi^{\prime}(0)=+\infty$. Note that the quality of the public school is the same for all children. From equations (2) and (3), it is clear that the quality of public education $e$ and the rate of growth of the economy are positively related. At this point, we can write the individual constraints as:

$$
c_{0}^{i}=\left(1-\tau-\lambda_{0}\right) h_{0}^{i}-s_{0}^{i},
$$

and

$$
c_{1}^{i}=R s_{0}^{i}+b_{1}^{i},
$$

where $s_{0}^{i}$ represents savings and $R=(1+r)$ is the return on savings.

We assume that the only political decision facing working generation in this economy is to vote on the level of the subsidy for public education, represented by the tax rate on labor income, $\tau$.

\section{The Pension System}

This section describes the pension system. We propose two alternatives. Both combine a PAYGO scheme with a funded scheme, but they differ in the design of the funded scheme. The funded scheme in the first system entails the set-up of Mandatory Individual Retirement Accounts (MIRAs). The second system combines the PAYGO scheme with the construction of a fund that the Social Security administration invests in assets. We call this scheme a Trust Fund system.

\subsection{PAYGO plus MIRAs}

The contribution in period 0 of a worker whose stock of human capital is $h_{0}^{i}$ is $\lambda_{0} h_{0}^{i}$.

This contribution is split into two parts. An amount $\lambda_{0}^{M} h_{0}^{i}$ goes to the MIRA of 
individual $i$. The remainder, $\lambda_{0}^{P} h_{0}^{i}$, is used to pay the PAYGO benefits of those currently retired in period 0 . We assume $\lambda_{0}^{M}, \lambda_{0}^{P} \geq 0$, and $\lambda_{0}^{M}+\lambda_{0}^{P}=\lambda_{0}$. Total revenue to the Social Security system in period 0 is:

$$
T_{0}=\int_{0}^{\infty}\left(\lambda_{0}^{M} h_{0}^{i}+\lambda_{0}^{P} h_{0}^{i}\right) d G\left(h_{0}^{i}\right)=\lambda_{0}^{M} h_{0}+\lambda_{0}^{P} h_{0}=\lambda_{0} h_{0} .
$$

The amount $\lambda_{0}^{M} h_{0}$ is invested in assets and serves to pay the MIRA benefits in period 1 , while $\lambda_{0}^{P} h_{0}$ is devoted to pay pensions in period 0 . In period 1 , there are two sources of funds for paying pensions. First is the amount $R \lambda_{0}^{M} h_{0}$, which is the capitalized value of all individual accounts. Second is the amount $\lambda_{1}^{P} h_{1}$, which comes from total future contributions in period $1, T_{1}$. Then, the average pension benefit in period 1 is:

$$
b_{1}=R \lambda_{0}^{M} h_{0}+\lambda_{1}^{P} h_{1},
$$

where $h_{1}$ is the average level of human capital in period 1.

However, in most pension systems, not all individuals enjoy the same benefits. The reason is twofold. First, the existence of individual accounts (the MIRA scheme). Second, the possibility that the PAYGO benefit be partly related to past contributions. To capture this second possibility, we define $D^{i}(\alpha)$ as a redistributive factor according to the expression:

$$
D^{i}(\alpha)=\left[\alpha+(1-\alpha) \frac{h_{0}^{i}}{h_{0}}\right], \text { where } \alpha \in[0,1] .
$$

To sum up, a worker of period 0 whose stock of human capital is $h_{0}^{i}$ gets the following pension benefit $b_{1}^{i}$ in period 1 :

$$
b_{1}^{i}=R \lambda_{0}^{M} h_{0}^{i}+\lambda_{1}^{P} h_{1} D^{i}(\alpha)=R \lambda_{0}^{M} h_{0}^{i}+\alpha \lambda_{1}^{P} h_{1}+(1-\alpha) \lambda_{1}^{P} \frac{h_{1}}{h_{0}} h_{0}^{i} .
$$

The benefit has three tiers. First, a MIRA benefit $R \lambda_{0}^{M} h_{0}^{i}$. Second, a universal pension benefit, $\alpha \lambda_{1}^{P} h_{1}$, which is unrelated to past contributions and is financed on a PAYGO basis. Third, a pension benefit which is also financed on a PAYGO basis, but whose amount is proportional to past contribution, $(1-\alpha) \lambda_{1}^{P} \frac{h_{1}}{h_{0}} h_{0}^{i}$.

If $\alpha=1$, all individuals get exactly the same PAYGO benefit, while if $\alpha=0$ the PAYGO benefits are proportional to past contributions. 
The pension system is always feasible since:

$$
\int_{0}^{\infty} b_{1}^{i} d G\left(h_{0}^{i}\right)=R \lambda_{0}^{M} \int_{0}^{\infty} h_{0}^{i} d G\left(h_{0}^{i}\right)+\lambda_{1}^{P} h_{1} \int_{0}^{\infty} D^{i}(\alpha) d G\left(h_{0}^{i}\right)=b_{1} .
$$

\subsection{PAYGO plus Trust Fund}

Under this system, some part of the contributions is diverted to build up a fund, instead of going to individual accounts. This fund is invested in assets by the Social Security administration and is used to help pay pension benefits in the next period. In particular, a fraction $\lambda_{0}^{T}$ of the contributions is diverted to the fund. As above, if an individual contributes $\lambda_{0} h_{0}^{i}$ to the system, the amount $\lambda_{0}^{P} h_{0}^{i}$ goes to pay current pensions, while $\lambda_{0}^{T} h_{0}^{i}$ goes to the fund. Again, we have $\lambda_{0}^{T}, \lambda_{0}^{P} \geq 0, \lambda_{0}^{T}+\lambda_{0}^{P}=\lambda_{0}$, and the total revenue is also $\lambda_{0} h_{0}$. The average pension is

$$
b_{1}=R \lambda_{0}^{T} h_{0}+\lambda_{1}^{P} h_{1} .
$$

The difference with the previous case is that now the benefits coming from the fund are subject to the same redistribution as the benefits that come from the PAYGO scheme. This means that individual $i$ get in period 1 a pension benefit equal to

$$
b_{1}^{i}=\left[\alpha+(1-\alpha) \frac{h_{0}^{i}}{h_{0}}\right]\left[R \lambda_{0}^{T} h_{0}+\lambda_{1}^{P} h_{1}\right] .
$$

Again, it is easy to see that this pension system is feasible. Summing up, in period 0 the Social Security system, either the MIRAs or the Trust Fund, is described by four parameters: $\lambda_{0}^{P}, \lambda_{1}^{P}, \lambda_{0}^{M}$ (or $\lambda_{0}^{T}$ ), and $\alpha$. This general framework allows us to consider several interesting particular cases:

Example 1: Fully funded mandatory individual retirement accounts $\left(\lambda_{0}^{P}=\lambda_{1}^{P}=\right.$ $\left.0 ; \lambda_{0}=\lambda_{0}^{M}\right)$

Every individual gets a pension which is simply the capitalized value of her contribution, and the system performs no redistribution at all:

$$
b_{1}^{i}=R \lambda_{0}^{M} h_{0}^{i}
$$

In this example the government merely imitates a private pension scheme. 
Example 2: Pure PAYGO $\left(\lambda_{0}^{M}=0 ; \lambda_{0}^{T}=0\right)$

The pension benefit of individual $i$ in period 1 is:

$$
b_{1}^{i}=\lambda_{1}^{P} h_{1} D^{i}(\alpha)=\alpha \lambda_{1}^{P} h_{1}+(1-\alpha) \lambda_{1}^{P} \frac{h_{1}}{h_{0}} h_{0}^{i}
$$

If $\alpha=1$, all individuals receive the same pension benefit, which is the average contribution in period 1 :

$$
b_{1}^{i}=\lambda_{1}^{P} h_{1} .
$$

The average pension depends only on the average stock of human capital in period 1. Pension systems in which all individuals get the same benefit are sometimes called Beveridgean. Countries where the pension system is approximately Beveridgean are Canada and The Netherlands.

If $\alpha=0$, pension benefits are proportional to past contributions:

$$
b_{1}^{i}=\lambda_{0}^{P} \frac{h_{1}}{h_{0}} h_{0}^{i} .
$$

Pension systems in which pensions are proportional to past contributions are called Bismarckian. Germany and France have such pension systems. For most pension systems in the world $\alpha$ lies somewhere between 0 and 1 .

Example 3: Fully Funded Trust System $\left(\lambda_{0}^{P}=\lambda_{1}^{P}=0 ; \lambda_{0}=\lambda_{0}^{T}\right)$

All the revenue that the system collects in period 0 is pooled together in a fund. The fund is invested in assets to pay pensions in period 1. However, there can be some degree of redistribution. In particular, the pension benefit is:

$$
b_{1}^{i}=\left[\alpha+(1-\alpha) \frac{h_{0}^{i}}{h_{0}}\right] R \lambda_{0}^{T} h_{0} .
$$

\section{Equilibrium}

Throughout this section, we fix all the parameters describing the Social Security system. Each worker has to choose a consumption stream and an ideal tax rate to fund education, $\tau$, taking into account her consumption decision. Finally, once every 
individual has chosen her preferred tax rate, society will choose a value for the tax rate with the property of being a Condorcet winner. ${ }^{9}$

As a benchmark, we first consider the case in which individuals can borrow against their pension benefits of period 1. In general, this possibility is ruled out by legislation (see Mulligan and Sala-i-Martin (1999)) and pension benefits cannot be used as collateral for a loan. However, this case is worth an analysis to facilitate the exposition of the general case, where borrowing against pensions is not allowed.

\subsection{Individuals may borrow against future pensions}

\section{Step 1: Savings}

Each middle-aged agent chooses her savings for period 1, taking the tax rate $\tau$ as given. The problem of individual $i$ is to maximize her utility, subject to the intertemporal budget constraint:

$$
\begin{array}{ll}
\max _{\left\{c_{0}^{i}, c_{1}^{i}\right\}} & u\left(c_{0}^{i}\right)+\rho u\left(c_{1}^{i}\right) \\
\text { s.t. } & c_{0}^{i}+\frac{c_{1}^{i}}{R}=y^{i},
\end{array}
$$

where $y^{i}$ is the present value of her lifetime income, that is, $y^{i}=\left(1-\tau-\lambda_{0}\right) h_{0}^{i}+\frac{b_{1}^{i}}{R}$. Since optimal savings can be either positive or negative, the following first-order condition is necessary and sufficient for a maximum:

$$
\frac{u^{\prime}\left[c_{0}^{i *}\right]}{u^{\prime}\left[c_{1}^{i *}\right]}=\rho R
$$

As preferences are homothetic, we know that the income expansion path in the space $\left(c_{0}^{i}, c_{1}^{i}\right)$ is a straight line that passes through the origin. That is, there is some positive constant $\Omega$ so that $c_{1}^{i *}=\Omega c_{0}^{i *}{ }^{10}$ This implies that the optimal levels of consumption $c_{0}^{i *}$ and $c_{1}^{i *}$ can be written as a constant fraction of intertemporal income $y^{i}$. We have $c_{0}^{i *}=\frac{R}{R+\Omega} y^{i}$ and $c_{1}^{i *}=\frac{R \Omega}{R+\Omega} y^{i}$. We can also define optimal savings as

\footnotetext{
${ }^{9} \mathrm{~A}$ given value of the tax rate is a Condorcet winner if it wins in majority voting against any other tax rate.

${ }^{10}$ In particular,

$$
\Omega=\frac{u^{\prime \prime}\left[c_{0}^{i *}\right]}{\rho R u^{\prime \prime}\left[c_{1}^{i *}\right]} .
$$
}


$s_{0}^{i *}=\left(1-\tau-\lambda_{0}\right) h_{0}^{i}-c_{0}^{i *} \cdot{ }^{11}$

Without a pension system, it is obvious that all individuals would have positive savings to finance retirement. Moreover, individuals with a high stock of human capital will save more than individuals with a low stock of human capital. However, when there is a pension system, some individuals may choose not to save. Intuitively, if the pension system is generous enough, poor workers can choose to borrow against their future pension benefits. Without any restriction on the parameters of the model, savings could even be decreasing in the stock of human capital. This would happen if the return of the pension system is higher than the return from savings and the payroll tax is large enough. Individuals have two ways of transferring income from period 0 to period 1 . They can either save or contribute to the pension system. If this second alternative yields a higher return than the first one, they will not be very eager to save. They will have negative private savings in period 0 and will use their Social Security payments in period 1 to consume and to repay their loans. We need the following assumption since we want to avoid this possibility.

Assumption 1 (i) $R>\frac{h_{1}}{h_{0}}$; (ii) $\lambda_{0}<\frac{\Omega}{\Omega+R} ;$ (iii) $\lambda_{1}^{P} \leq \lambda_{0}^{P}$.

Part (i) says that the return on capital is always greater than the rate of growth of human capital. It implies that, on average, a pure PAYGO system always gives a lower return than a pure FF system. This assumption provides the major justification for Social Security reform (see Feldstein (1996), (1998) and Kotlikoff (1996)). ${ }^{12}$ If the opposite were true, it would be difficult to argue in favor of a reform of the pension system. Part (ii) imposes an upper bound on the payroll tax or a lower bound on

${ }^{11}$ As an example, consider the following utility function:

$$
u(c)= \begin{cases}\frac{1}{1-\gamma} c^{1-\gamma} & \text { for } \gamma \neq 1 \\ \ln (c) & \text { for } \gamma=1\end{cases}
$$

Then $\Omega=(\rho R)^{1 / \gamma}$, and optimal consumption levels are $c_{0}^{i *}=\frac{R}{R+\rho^{1 / \gamma} R^{1 / \gamma}} y^{i}$ and $c_{1}^{i *}=\frac{R^{1+1 / \gamma} \rho^{1 / \gamma}}{R+\rho^{1 / \gamma} R^{1 / \gamma}} y^{i}$.

${ }^{12}$ As $R>\frac{h_{1}}{h_{0}}$, one possible criticism to our model is that the PAYGO system is not the most efficient way to achieve within-generation redistribution. We have two answers to this criticism. First, we are not interested in this paper in justifying the existence of a PAYGO system, that we take for granted. Second, if we were to justify the existence of a PAYGO system, we would use a political argument. In particular, we can provide a condition that guarantees that the decisive voter prefers a PAYGO system rather than a Funded System. We discuss briefly this issue in the Appendix. 
the slope $\Omega$. Part (iii) requires that the size of the PAYGO scheme will not rise from period 0 to period 1 . We have the following proposition (see the Appendix for a proof).

Proposition 1 Suppose Assumption 1 holds. Then, there exists a strictly positive number $\bar{\tau}$, such that for all $\tau$ belonging to the interval $[0, \bar{\tau}]$, savings are increasing with the stock of human capital. Moreover, $\bar{\tau}>1-\lambda_{0}\left(\frac{\Omega+R}{\Omega}\right)>0$.

In order to illustrate the proposition, suppose that the utility function is $u=\ln (c)$. In that case, $\Omega=\rho R$. We set $\rho=0.55$ as in Barro and Sala-i-Martin (1999). Part (ii) of Assumption 1 implies $\lambda_{0}<0.355$. Then, if $\lambda_{0}=0.1 \bar{\tau}>0.72$. If $\lambda_{0}=0.2$ $\bar{\tau}>0.44$. If $\lambda_{0}=0.3, \bar{\tau}>0.15$. This gives an idea of the range of admissible values of the parameters. In the sequel, we assume that $\tau<\bar{\tau}$, which guarantees that savings are increasing with the stock of human capital. Another implication of Assumption 1 is the following: if the savings of an individual with a stock of human capital $h_{0}^{i}$ are strictly positive, this will also be the case for all individuals with a stock of human capital greater than $h_{0}^{i}$.

\section{Step 2: The tax rate}

Given her optimal consumption decision, each individual has to choose her ideal tax rate, $\tau$. We plug the optimal values $c_{0}^{i *}$ and $c_{1}^{i *}$ into the utility function and we use the private budget constraints (7) and (8), the human capital accumulation rule (5) and the government budget constraint (6), to obtain the indirect utility function $V^{i}(\tau)$. Eliminating constant terms, we see that maximizing her indirect utility function consists simply of maximizing the present value of her lifetime income $y^{i} .{ }^{13}$ We write $y^{i}(\tau)$ to stress the dependence on the tax rate. Since $y^{i}(\tau)$ is strictly concave with respect to $\tau,{ }^{14}$ the ideal tax rate for individual $i$, which we call $\tau^{i}$, satisfies the first order condition:

$$
h_{0}^{i}=\frac{1}{R} \frac{\partial b^{i}\left(\tau^{i}\right)}{\partial \tau}=\frac{1}{R} \lambda_{1}^{P} D^{i}(\alpha) \frac{\partial h_{1}\left(\tau^{i}\right)}{\partial \tau} .
$$

\footnotetext{
${ }^{13}$ Note that this is a direct implication of Fisher's Separation Theorem.

${ }^{14}$ In the Appendix we prove that $y^{i}(\tau)$ is strictly concave.
} 
The the left-hand side is the marginal cost of the tax for education, while the term on the right is its marginal benefit through the positive effect that public education has on the pension benefit of period 1 . The right-hand side decreases with $\tau$, which means that this positive effect has diminishing returns.

From (23) we see that the higher the stock of human capital of an individual is, the lower her preferred tax rate is. Then, there is a Condorcet winner $\tau^{*}$, which corresponds to the ideal tax rate of the individual whose stock of human capital is the median of the distribution, namely $h_{0}^{m}$. That is, $\tau^{*}=\tau^{m}$.

\subsection{Introducing borrowing constraints}

Now we study the case in which savings are constrained to be non-negative. In the sequel, therefore, we impose the constraint that $s_{0}^{i} \geq 0$. Those individuals for whom the constraint is binding are called saving-constrained individuals. We will see that all saving-constrained individuals vote for a lower tax rate than the one they would have chosen if they were allowed to borrow.

Savings are as follows:

$$
s_{0}^{i *}(\tau)= \begin{cases}\left(1-\tau-\lambda_{0}\right) h_{0}^{i}-c_{0}^{i *} & \text { if } \tau \leq \widehat{\tau}^{i} \\ 0 & \text { if } \tau>\widehat{\tau}^{i}\end{cases}
$$

where $\widehat{\tau}^{i}$ is defined implicitly by setting $s_{0}^{i}=0$ in the first-order condition (22). So, $\widehat{\tau}^{i}$ is defined by:

$$
u^{\prime}\left[\left(1-\widehat{\tau}^{i}-\lambda_{0}\right) h_{0}^{i}\right]-\rho R u^{\prime}\left[b_{1}^{i}\left(\widehat{\tau}^{i}\right)\right]=0
$$

This cut-off value of the tax rate for individual $i$ has the following interpretation. Suppose that borrowing is allowed. Then, individual $i$ would like to borrow against her pension benefit whenever $\tau>\widehat{\tau}^{i}$. As this is banned, her savings are zero for any value of $\tau>\widehat{\tau}^{i}$. We can check that $\widehat{\tau}^{i}$ grows along with the stock of human capital. This implies that, when the tax rate is low, only individuals with a low stock of human capital are saving-constrained. As the tax rate rises, the proportion of saving-constrained individual also rises.

Our next task is to see which is now the preferred tax rate of every individual. For our purposes, it is necessary to study the shape of the indirect utility function. 
We define $V^{i r}(\tau)$ as the function obtained by setting $s_{0}^{i}=0$ in the utility function of individual $i$.

$$
V^{i r}(\tau)=u\left[\left(1-\tau-\lambda_{0}\right) h_{0}^{i}\right]+\rho u\left[b_{1}^{i}(\tau)\right] .
$$

The indirect utility function of $i$ when borrowing is not allowed is the following:

$$
W^{i}(\tau)= \begin{cases}V^{i}(\tau) & \text { for } \tau \leq \widehat{\tau}^{i} \\ V^{i r}(\tau) & \text { for } \tau>\widehat{\tau}^{i}\end{cases}
$$

We are going to prove that $W^{i}(\tau)$ is single-peaked. Suppose we extend the function $V^{i r}(\tau)$ to the whole interval $[0,1]$. It has the following properties:

i) It is strictly concave.

ii) It is always strictly below $V^{i}(\tau)$, except at $\widehat{\tau}^{i}$, where their graphs are tangent to each other.

iii) It attains a maximum at $\tau^{i r}<\tau^{i}$.

$i v)$ Again, the higher the stock of human capital is, the lower $\tau^{i r}$ is.

Properties (i), (ii), and (iv) are immediate. We prove Property (iii). To simplify notation, we write $V^{i r}(\tau)=u\left[\widehat{c_{0}^{i}}\right]+\rho u\left[\widehat{c_{1}^{i}}\right]$, where $\widehat{c_{0}^{i}}=\left(1-\tau-\lambda_{0}\right) h_{0}^{i}$ and $\widehat{c_{1}^{i}}=b_{1}^{i}(\tau)$. The preferred tax rate for a saving-constrained individual satisfies the following firstorder condition:

$$
V^{i r \prime}\left(\tau^{i r}\right)=-h_{0}^{i} u^{\prime}\left[\widehat{c_{0}^{i}}\right]+\rho \frac{\partial b_{1}^{i}\left(\tau^{i r}\right)}{\partial \tau} u^{\prime}\left[\widehat{c_{1}^{i}}\right]=0
$$

Rewriting, we have:

$$
h_{0}^{i} \frac{u^{\prime}\left[\widehat{c_{0}^{i}}\right]}{\rho R u^{\prime}\left[\widehat{c_{1}^{i}}\right]}=\frac{1}{R} \frac{\partial b_{1}^{i}\left(\tau^{i r}\right)}{\partial \tau} .
$$

From condition (22) we know that $\frac{u^{\prime}\left[c_{0}^{i *}\right]}{\rho R u^{\prime}\left[c_{1}^{i *}\right]}=1$. At $\left(\widehat{c_{0}^{i}}, \widehat{c_{1}^{i}}\right)$ the individual is savingconstrained, which means that $\widehat{c_{0}^{i}}<c_{0}^{i *}$ and $\widehat{c_{1}^{i}}>c_{1}^{i *}$. But then, $\frac{u^{\prime}\left[\widehat{c}_{0}^{i}\right]}{\rho R u^{\prime}\left[\widehat{c}_{1}^{i}\right]}>1$. This implies that $\tau^{i r}<\tau^{i}$. It is interesting to see the intuition behind the inequality $\tau^{i r}<\tau^{i}$. When an individual cannot borrow, her consumption in period 0 is lower and her consumption in period 1 is higher than the corresponding consumptions of her unrestricted optimum (when borrowing is possible). In other words, her consumption is too large in period 1 and it is too small in period 0 . The only way of getting closer to her (unrestricted) optimal consumption stream is by choosing a lower tax rate in period 0 . Now we have the following: 
Lemma 2 For all $i$, the indirect utility function $W^{i}(\tau)$ is single-peaked.

Proof. The function $W^{i}(\tau)$ can have three different shapes, depending on the relationship between $\tau^{i}$ (the preferred tax rate without restrictions on savings) and $\widehat{\tau}^{i}$ : Case 1: $\tau^{i}<\widehat{\tau}^{i}$. Then, $W^{i}(\tau)$ is single-peaked since, to the right of $\widehat{\tau}^{i}, W^{i}(\tau)=V^{i r}(\tau)$ and $V^{i r}(\tau)$ is a decreasing function to the right of $\widehat{\tau}^{i}$. The preferred tax rate is still $\tau^{i}$.

Case 2: $\tau^{i}>\widehat{\tau}^{i}$. To the right of $\widehat{\tau}^{i}, W^{i}(\tau)=V^{i r}(\tau)$. As both $V^{i}(\tau)$ and $V^{i r}(\tau)$ are strictly concave and $V^{i}\left(\widehat{\tau}^{i}\right)=V^{i r}\left(\widehat{\tau}^{i}\right)$, the preferred tax rate of $i$ is $\tau^{i r}$, and not $\tau^{i}$. Moreover, we can prove that $\tau^{i r}<\tau^{i}$. This follows from the first order conditions (23) and (29).

Case 3: $\tau^{i}=\widehat{\tau}^{i}$. In this case we also have $\tau^{i}=\tau^{i r}$. The preferred tax rate of this agent is $\tau^{i}$.

As a Corollary of the above lemma, the decisive agent is that individual whose stock of human capital is the median of the distribution. If she has positive savings, then $\tau^{*}=\tau^{m}$. If, on the contrary, she is saving-constrained, $\tau^{*}=\tau^{m r}<\tau^{m}$. ${ }^{15}$

In the next section, we study several proposals to reform the pension system and their effect on the budget for public education.

\section{Social Security Reform}

\subsection{Prefunding and Privatization}

We focus on a pension system of the type described in Section 3.1, that is, a system that combines a PAYGO scheme with MIRAs. In particular, we study the effect of an increase in the funded scheme at the expense of the PAYGO scheme. This is the reason why we refer to this type of reform as "prefunding" and "privatization." Here increasing funding can be seen as promoting privatization of the pension system, since the funds diverted from the PAYGO scheme are used to build up individual accounts. Most of the proposed reforms of Social Security entail a diversion of funds towards individuals retirement accounts. This is because MIRAs normally yield, on

\footnotetext{
${ }^{15}$ Also note that our assumption that $\varphi^{\prime}(0)=+\infty$ implies that $\tau^{*}>0$.
} 
average, a higher return than the PAYGO scheme. Within our model, this means that $R>\frac{h_{1}}{h_{0}}$, Part (i) of Assumption 1. However, two caveats are in order. First, even when a funded scheme pays a higher return on average, this does not mean that all individuals get a higher return under a funded scheme. If the original PAYGO scheme is highly redistributive ( $\alpha$ is very high), moving towards individual accounts likely hurts those individuals with low wages. Second, the reform entails always transition costs. Simply comparing between the return on assets and on Social Security taxes is misleading. It amounts to comparing only two steady states of two different worlds (see Diamond (2000)). While the working cohort contributes more to the funded scheme, somebody has to pay for current pension benefits. This is sometimes called the implicit debt of the system. To illustrate these issues, we consider three different possibilities of reform. The three proposals entail an increase in the contributions to the MIRAs, starting in period 0. They differ from the proposed change in the PAYGO scheme. In the first reform, the entire cost of the transition is borne by current workers. In the second reform, there is a reduction in the PAYGO scheme in both periods of the same size of the increase in the MIRAs. In the third reform, the PAYGO scheme remains unchanged.

\section{First type of Reform}

We start with a reform in which the entire cost of the transition is paid by period 0 workers. Pensions for those who are retired in period 0 are cut. On the contrary, future pensions of current workers lose part of the PAYGO benefit. For example, suppose that the initial pay-roll tax is $20 \%$, from which a $1 \%$ goes to the MIRAs, and a $19 \%$ goes to the PAYGO scheme. This means that initially, $\lambda_{0}=0.2$, and $\left(\lambda_{0}^{P}, \lambda_{0}^{M}\right)=\left(\lambda_{1}^{P}, \lambda_{1}^{M}\right)=(0.19,0.01)$. After the reform, workers are required to increase their contributions to the MIRAs, and the PAYGO scheme is reduced accordingly, but only from period 1 onwards. Therefore, total contributions in period 1 will remain the same after the reform as total contributions in period 0 before reform. In this way, only period 0 workers pay for the cost of transition. For example, suppose $\left(\lambda_{0}^{P^{\prime}}, \lambda_{0}^{M \prime}\right)=(0.19,0.03)$ and $\left(\lambda_{1}^{P^{\prime}}, \lambda_{1}^{M \prime}\right)=(0.17,0.03)$. Then, the total contributions in each period after the reform are $\lambda_{0}^{\prime}=0.22$ and $\lambda_{1}^{\prime}=\lambda_{0}=0.2$, respectively. 
With this reform, pensions paid to the currently retired in period 0 do not change. On the contrary, all workers will have less intertemporal income after the reform. They increase their contributions to the MIRAs. In turn, they get an increase in their pensions which is exactly the capitalized value of their increased contributions. Still, their PAYGO benefits are reduced.

To study the effect of this reform on the support for public education, we have to consider two different cases depending on whether the median voter is savingconstrained or not.

(i) The median voter is not saving-constrained. Condition (23) applies in this case. The left-hand side is not affected by this reform. The reform only affects the righthand side. But it is obvious that the effect of this reform is to reduce the positive impact of public education on future pensions. We can see that:

$$
\frac{\partial b^{i}\left(\tau^{i}\right)}{\partial \tau}=\lambda_{1}^{P} D^{i}(\alpha) \frac{\partial h_{1}\left(\tau^{i}\right)}{\partial \tau}
$$

As this reform entails a reduction in $\lambda_{1}^{P}$, the term $\partial b^{i} / \partial \tau$, which represents the marginal benefit of the taxes for education, decreases. This implies that the median now voter prefers a lower tax rate.

(ii) The median voter is saving-constrained. In this case we must see what happens to the first order condition (29). As the payroll tax in period 0 increases, the lefthand side, which represents the marginal cost of the taxes for education, rises. The right-hand side represents the marginal benefit from the taxes for education. This term is lower after the reform. Then, it is immediate that the effect on the tax rate is negative. The intuition behind this result is simple. As the median voter has less intertemporal income, the only way to get closer to her previous choice is by choosing a lower tax rate. This is now less costly in terms of future pensions since, after the reform, the positive impact of public education on future pensions has reduced.

\section{Second Type of Reform}

We saw in the previous example that, if workers are forced to pay the whole cost of the transition, there is a negative impact on the revenue to finance public education. Now we move to the other polar case. We study a proposal of reform 
which transfers resources from the PAYGO scheme to the MIRAs, without changing the total contribution to the system. If no additional resources are used, this implies an immediate reduction of the pension benefits paid to the old in period 0 . This means that the initial cost of the transition (in period 0) is paid in full by the old. Although we believe that this reform is hardly feasible, the example is interesting because, at first sight, it seems that it will have little or no impact on the support for public education.

As above, suppose that initially, $\left(\lambda_{0}^{P}, \lambda_{0}^{M}\right)=\left(\lambda_{1}^{P}, \lambda_{1}^{M}\right)=(0.19,0.01)$. After the reform, workers are required to increase their contributions to the MIRAs. In addition, the part that goes to the PAYGO scheme is reduced. For example, $\left(\lambda_{0}^{P^{\prime}}, \lambda_{0}^{M^{\prime}}\right)=$ $\left(\lambda_{1}^{P \prime}, \lambda_{1}^{M \prime}\right)=(0.17,0.03)$. Total contributions have not changed, that is, $\lambda_{0}^{\prime}=\lambda_{1}^{\prime}=$ $\lambda_{0}=0.2$.

We distinguish again two cases so as to analyze the effect of this reform on the equilibrium level of the tax rate that finances public education:

(i) The median voter is not saving-constrained. From condition (23) we see that the effect is the same as with the previous reform. This means that increasing $\lambda_{0}^{M}$ at the expense of $\lambda_{1}^{P}$ has the same negative effect irrespective of whether the cost of the transition is paid by the current workers or by the retired workers.

(ii) The median voter is saving-constrained. From condition (29) we see that the effect on the tax rate is again negative. This negative effect, however, is now less severe, since the marginal cost does not change.

Interestingly, even when the burden of the transition is paid mainly by the old, the effect on the subsidy for public education, which is paid by the current workers, is negative.

Third Type of Reform: An "Incremental Reform"

In this third reform, the PAYGO scheme does not change and workers are required to increase their contributions to the MIRAs. For example, consider a change from $\left(\lambda_{0}^{P}, \lambda_{0}^{M}\right)=\left(\lambda_{1}^{P}, \lambda_{1}^{M}\right)=(0.19,0.01)$ to $\left(\lambda_{0}^{P \prime}, \lambda_{0}^{M^{\prime}}\right)=\left(\lambda_{1}^{P \prime}, \lambda_{1}^{M \prime}\right)=(0.19,0.03)$. Total contributions have increased from $\lambda_{0}=0.2$ to $\lambda_{0}^{\prime}=\lambda_{1}^{\prime}=0.22$.

In period 0 pensions remain unchanged. In contrast, current workers have to pay 
a greater contribution today, $\lambda_{0}^{\prime}$, but their pension benefits also increase in such a way that they have the same intertemporal income. Thus, this reform is simply a way of increasing savings in period 0 , and it implies a sacrifice in consumption today in exchange for consumption tomorrow. However, some workers may be worse-off after the reform. This is so for workers who are saving-constrained. They would like to increase consumption in period 0 , at the cost of reducing consumption in period 1 , but they cannot, since borrowing is not allowed. And this reform takes additional income from period 0 and transfers it to period 1, moving this group of individuals even farther from their optimum.

The impact of this reform on the subsidy to finance public education depends on whether the median voter is saving-constrained or not:

(i) The median voter is not saving-constrained. From condition (23), we see that neither the left-hand side nor the right-hand side change. This means that this reform does not affect the tax rate.

(ii) The median voter is saving-constrained. We study the first order condition (29). The effect is exactly the same as in the first reform. The marginal cost rises and the marginal benefit gets lower. Then, the tax rate preferred by the median voter is lower after the reform.

Our previous analysis reveals that any reform of the pension system that weakens this "link" between the pension system and public education, generates less support for funds for public education. These reforms affect the rate of return on the individuals' contribution to public education, through the reduced PAYGO scheme and, consequently, the willingness of society to pay taxes to finance education changes. Naturally, as the output growth rate is endogenous in our framework and, on the other hand, depends on the investment in public education, the overall rate of growth of the economy may decrease. It is also remarkable that, even in the case of a reform that does not affect that link, a negative impact on the support for public education can emerge. This can happen in the presence of borrowing constraints. The existence of borrowing constraint restricts the share of disposable income that the median-voter can devote to current consumption. The last type of reform that we 
have considered increases future consumption (via a higher pension benefit) by lowering current consumption (by increasing the pay-roll tax). Therefore, the median voter tries to restore her "initial" restricted optimum by voting for less funds for public education. As a result, the output growth rate decreases.

\subsection{Prefunding without Privatization}

At last, in order to complete our analysis of the effects of reforming the social security system on taxes to finance public education, we must also study what would happen in an hypothetical case in where these funds diverted from the PAYGO scheme are used to build up a fund. In this way, the Social Security administration could try to take advantage of the higher rate of return existing in the capital markets. According to our Assumption 1, the average return of the system rises by creating this fund. We call this type of reform Prefunding without Privatization since under this particular proposal both the PAYGO and the Funded scheme are subject to the same redistribution factor (see Subsection 3.2).

We found out that this design of the system involves that qualitative identical results for the tax rate, $\tau$, can be established for the three reforms considered. We skip the details, as it is a tedious repetition of the previous analysis.

\section{Conclusion}

We analyzed how different proposals for reforming Social Security may affect the support for public funding of education in the political process by which the educational tax is determined. In our model, public funding of education increases the return of the social security system by improving the human capital of next period workers. In this context, current voters can expect to benefit from the growth process through the increased qualification of labor and, consequently the higher future wages. All our results are about the impact of exogenous changes in the pension system on the education tax, that is endogenously chosen. We ignore the endogenous choice of the tax to finance the pension system to avoid the problem of voting on a multidimensional policy space, where typically equilibrium fails to exist. 
Our results suggest that most of the reforms considered entail a negative effect on the educational tax rate. We find no effect in the so-called "incremental" reform, provided that the median income individual is not saving-constrained. Nevertheless, according to Poterba, Venti and Wise (1996), individuals save little saving for retirement, mostly due to the existence of Social Security. The median financial assets of households with heads aged 55-64 was only $\$ 8,300$ in 1991 , substantially less than six months income. Except for Individual Retirement Accounts (IRAs) and 401(k) balances, the median was less than $\$ 3,000$. Almost 20 percent of families had no financial assets at all. This means that the most plausible case from an empirical point of view is a situation in which the median voter is saving-constrained, giving additional support to the situation in which the reform of Social Security has a negative impact on the support for public education.

A possible criticism of our model is that only middle-aged agents take decisions about the financing of public education. In the case of young agents, this can be easily justified if they are under the legal age to vote. In addition, we can consider countries where there exists a mandatory education period and entry to labor markets is restricted for young agents. On the other hand, we put aside the role played by the old in the choice of fiscal policies, because we wish to focus on the possible effects that these reforms have on the accumulation of human capital. In fact, if assuming that the old vote adds complexity to the model without changing the qualitative results on the political support for public education.

A more general model including intergenerational altruism would modify the quantitative but not the qualitative findings of our model.

A simplified economy was examined here in order to clarify some aspects of the social security reform that has not been studied in depth. We may draw the following lesson: when proposing reforms of Social Security, they must be analyzed carefully in case these reforms could have negative impacts on other public programs that affect the well-being of different generations. 


\section{Appendix}

\section{Proof of Proposition 1}

To check whether optimal savings are increasing in the stock of human capital, we use the First Order Condition (22) to compute $\frac{\partial s_{0}^{i *}}{\partial h_{0}^{i}}$. This condition can be written as:

$$
u^{\prime}\left[\left(1-\tau-\lambda_{0}\right) h_{0}^{i}-s_{0}^{i *}\right]-\rho R u^{\prime}\left[R s_{0}^{i *}+b_{1}^{i}\right]=0 .
$$

Then, by Implicit Function Theorem,

$$
\frac{\partial s_{0}^{i *}}{\partial h_{0}^{i}}=\frac{u^{\prime \prime}\left[c_{0}^{i *}\right]\left(1-\tau-\lambda_{0}\right)-\rho R u^{\prime \prime}\left[c_{1}^{i *}\right] \frac{\partial b_{1}^{i}}{\partial h_{0}^{i}}}{u^{\prime \prime}\left[c_{0}^{i *}\right]+\rho R^{2} u^{\prime \prime}\left[c_{1}^{i *}\right]} .
$$

As $u$ is concave, this expression is positive provided the numerator is negative. We consider only the case in which the pension benefit follows the MIRAs pension system scheme, since the Trust Fund system is quite similar. Then, we have that savings will rise with the stock of human capital if

$$
\left(1-\tau-\lambda_{0}\right) \Omega \geq \lambda_{0}^{M} R+\lambda_{1}^{P}(1-\alpha) \frac{h_{1}}{h_{0}} .
$$

Recall that $\Omega=\frac{u^{\prime \prime}\left[c_{0}^{i *}\right]}{\rho R u^{\prime \prime}\left[c_{1}^{i *}\right]}$ is constant across individuals. When $\tau=0$, the condition is:

$$
\left(1-\lambda_{0}\right) \Omega>R \lambda_{0}^{M}
$$

since $h_{1}(\tau=0)=0$. But (32) is a consequence of part (ii) of Assumption 1. To see this, note that $\lambda_{0}<\frac{\Omega}{\Omega+R} \Rightarrow \lambda_{0}(\Omega+R)<\Omega \Rightarrow\left(1-\lambda_{0}\right) \Omega>R \lambda_{0} \geq R \lambda_{0}^{M}$. When $\tau>0$, the left-hand side of equation (31) is a decreasing function of $\tau$, while the right-hand side is an increasing function of $\tau$, since $h_{1}$ is increasing in $\tau$. Then, there is a cut-off value for the tax rate $\tau$, which we call $\bar{\tau}$. Condition (31) is true for all $\tau<\bar{\tau}$. By part (i) of Assumption 1, the right-hand side in equation (31) is always lower than $R\left(\lambda_{0}^{M}+\lambda_{1}^{P}(1-\alpha)\right.$ ), which in turn, by (iii), is also lower than $\lambda_{0} R$. As the right-hand side is lower than $\lambda_{0} R, \bar{\tau}$ is above that value of $\tau$ that solves $\left(1-\tau-\lambda_{0}\right) \Omega=\lambda_{0} R$, which is $1-\lambda_{0}\left(\frac{\Omega+R}{\Omega}\right)$. By part (ii) of Assumption 1, we obtain that $1-\lambda_{0}\left(\frac{\Omega+R}{\Omega}\right)>0$. 


\section{A condition that guarantees that a PAYGO system is preferred by a ma- jority of the population}

If workers alone decide which system of Social Security should prevail, the following condition guarantees that the median voter prefers a PAYGO system, rather than a Funded system:

$$
\frac{h_{0}^{m}}{h_{0}}<\frac{\alpha\left(\frac{h_{1}}{h_{0}}\right)}{R-\left(\frac{h_{1}}{h_{0}}\right)(1-\alpha)}
$$

or

$$
\frac{h_{1}}{h_{0}}>R \frac{\frac{h_{0}^{m}}{h_{0}}}{\alpha+(1-\alpha) \frac{h_{0}^{m}}{h_{0}}} .
$$

To illustrate this condition, we present the following example:

Example 1 Let $\frac{h_{0}^{m}}{h_{0}}=.75$, and $R=3.24$ (if annual interest rate is $4 \%$ and each period has 30 years, then $\left.R=(1.04)^{30}=3.2434\right)$. By Assumption $1, \frac{h_{1}}{h_{0}}<3.24$. The above condition sets a lower bound for the ratio $\frac{h_{1}}{h_{0}}$. This lower bound depends on the parameter $\alpha$. If $\alpha=1 / 2$ the condition requires $\frac{h_{1}}{h_{0}}>2.78$. If $\alpha=1$, it requires $\frac{h_{1}}{h_{0}}>2.43$.

Alternatively, we could think of this condition as a requirement on the value of $\alpha$. In particular, it must be high enough. This is obvious since, when $\alpha=0$, nobody wants a PAYGO system.

\section{Proof of the concavity of $y^{i}(\tau)$}

We compute the second derivative of $y^{i}(\tau)$ with respect to $\tau$ :

$$
\frac{\partial^{2} y^{i}(\tau)}{\partial \tau^{2}}=\frac{1}{R} \frac{\partial^{2} b_{1}^{i}(\tau)}{\partial \tau^{2}}=\frac{1}{R} \lambda_{1}^{P} D^{i}(\alpha) \frac{\partial^{2} h_{1}(\tau)}{\partial \tau^{2}} .
$$

The sign of $\frac{\partial^{2} y^{i}(\tau)}{\partial \tau^{2}}$ is that of $\frac{\partial^{2} h_{1}\left(\tau^{i}\right)}{\partial \tau^{2}}$. But the sign of $\frac{\partial^{2} h_{1}\left(\tau^{i}\right)}{\partial \tau^{2}}$ is negative since

$$
\frac{\partial^{2} h_{1}^{i}(\tau)}{\partial \tau^{2}}=\left(\theta_{e e}\left(e, h_{0}^{i}\right)\left(\varphi^{\prime}(e)\right)^{2}+\theta_{e}\left(e, h_{0}^{i}\right) \varphi^{\prime \prime}(e)\right)\left(h_{0}\right)^{2}<0 .
$$




\section{References}

[1] Barro, R. J. and X. Sala-i-Martin (1999): Economic Growth, The MIT Press.

[2] Becker, G. S. and K. H. Murphy (1986): "The Family and the State." Journal of Law and Economics 31, 1-18.

[3] Becker, G. S., K. H. Murphy and R. Tamura (1990): "Human Capital, Fertility and Economic Growth.” Journal of Political Economy, 98, S12-S37.

[4] Belletini, G. and C. Berti-Ceroni (1999): "Is Social Security really bad for growth?" Review of Economic Dynamics 2, 796-819.

[5] Boldrin, M. and A. Montes (2004): "The Intergenerational State. Education and Pensions." Review of Economic Studies, forthcoming.

[6] De Gregorio, J. (1996): "Borrowing Constraints, Human Capital Accumulation, and Growth." Journal of Monetary Economics 37, 49-71.

[7] Diamond, P. (2000): "Towards an Optimal Social Security Design." CeRP Working Paper No. 4/2000.

[8] Eckstein, Z., and I. Zilcha (1994): "The Effects of Compulsory Schooling on Growth, Income Distribution and Welfare." Journal of Public Economics 54, 339-359.

[9] Education at a Glance, 2002 edition, OECD, Paris, 2002.

[10] Feldstein, M. (1996): "The Missing Piece in Policy Analysis: Social Security Reform." American Economic Review 86 (2), 1-14.

[11] Feldstein, M. (1998): Privatizing Social Security (M. Feldstein Ed.), NBER, The University of Chicago Press.

[12] Galor, O., and D. Tsiddon (1997): "The Distribution of Human Capital and Economic Growth." Journal of Economic Growth 2, 93-124. 
[13] Geanokoplos, J., O. S. Mitchell and S. P. Zeldes (1998): "Would a Privatized Social Security System really Pay a Higher Rate of Return." In Framing the Social Security Debate: Values, Politics, and Economics (R. Douglas Arnold, Michael J. Graetz and Alicia H. Munnell, eds.), pp. 137-157, Brookings Institution Press.

[14] Glomm and Ravikumar (1992): "Public Versus Private Investment in Human Capital: Endogenous Growth and Income Inequality." Journal of Political Economy 100, 818-834.

[15] Gruber, J. and D. A. Wise (1999): Social Security and Retirement around the World, NBER, The University of Chicago Press.

[16] Gruber, J. and D. A. Wise (2001): "Different Approaches to Pension Reform from an Economic Point of View." In Coping with the Pension Crisis: Where Does Europe Stand? (M. Feldstein and H. Siebert, eds.), The University of Chicago Press.

[17] Kaganovich, M. and I. Zilcha (1999): "Education, social security and growth." Journal of Public Economics 71, 289-309.

[18] Kotlikoff, L. (1996): "Privatization of Social Security: How it works and why it matters." Tax Policy and the Economy 10, 1-32.

[19] Lucas, R. E., Jr. (1988): "On the Mechanics of Economic Development." Journal of Monetary Economics 22, 3-42.

[20] Mulligan, C., and X. Sala-i-Martin (1999): "Social Security in Theory and Practice (I): Facts and political Theories.” NBER Working Paper No. 7118.

[21] Pogue, T. F. and L. G. Sgontz (1977): "Social Security and Investment in Human Capital." National Tax Journal 30, 157-169.

[22] Poterba, J. M., S. F. Venti, and D. A. Wise (1996): "How Retirement Saving Programs increase Savings." Journal of Economic Perspectives 10 (4), 91-112. 